\title{
EDITORIAL
}

\section{FEELING, FAILURE, FALLACIES}

\section{Christian Ulrik Andersen \& Geoff Cox}

APRJA Volume 8, Issue 1, 2019

ISSN 2245-7755

CC license: 'Attribution-NonCommercial-ShareAlike'. 


\section{Feeling}

Digital culture has become instrumental for capturing and managing what Raymond Williams would once have called "structures of feeling". The journal issue A PeerReviewed Journal About Machine Feeling alludes to this, and points to a material analysis of aesthetics and culture, including its technical and social forms, and in the way that this concept was originally employed as an acknowledgment of the importance of the hard to capture dimensions of everyday life. Styles, expressions and sentiments are always in flux, yet Williams, and others after him, have with this term argued that they are grounded in cultural history and specific everyday situations. In developing a critical and analytic understanding we should therefore turn our attention to changes in language, style, aesthetics and those social forms which are active in the present, but not yet fully formed or captured by a conceptual or scientific knowledge framework. Taking their point of departure from Williams, Devika Sharma and Frederik Tygstrup write:

\section{We recognise the facts of cultural life once they are established and institutionalised, but we tend to miss those moments when new patterns of experience emerge, when people start to think differently, when new sensibili- ties arise, when habits swerve. (4)}

This journal issue further explores this line of thinking, and more specifically responds to the current developments in machine learning and the ability of technologies to capture and structure feelings and experiences that are active, in flux, and in the present; for example, in the ways that automated experiences of seeing and reading begin to produce knowledge through the capture of everyday styles, expressions, preferences, sentiments, and so forth - the very means that Williams alludes to.

If, in general, machine learning appears to lack an affective dimension, then in what ways are we to understand its resolute and concerted pursuit of this? What old registers of processing culture and organizing time, space and power does it build on? What potential new sensibilities and structures of feeling may arise in such normalized registers of our habits? What new cultural and social forms and practices emerge in the coming together of machine learning and structures of feeling? In each their own way, the authors in this journal explore these questions.

\section{Failure}

To capture moments when new patterns of experience emerge, when people start to think differently, when new sensibilities arise will first and foremost depend on a large set of training data - sound, text, biological data, and more that can be used for image recognition, sentiment analysis and more. At a more general level, these datasets absorb all kinds of social and cultural production; they seek to absorb every moment that people start to think, act, sense, and experience phenomena in new ways.

There is a certain paradox in this. As pointed out by Matteo Pasquinelli, machine learning is a paradigm of intelligence that fails to provide a methodology of failure. What people generally refer to as artificial intelligence and machine learning is merely a statistical mapping of correlations in the dataset. Because of this, machine learning will reduce the least common structures in the dataset, simply in order to reduce calculation costs. Consequently, machine learning is not a sign of cognition, but of compression 
as a means to efficiency, which on the other side is also a loss of diversity; failure does not exist. In this, he claims, machine learning seems much more aligned with a history of optical lenses who operate by resolutions and diffraction. This is what he calls statistical cinema. This problem of generalization or "regression towards the mean" is mathematical but not without political consequences.

\section{Fallacies}

What then is the role of researching digital culture and machine feeling? On the one hand, to follow Williams and capture the "habits that swerve" seems to be relegated to corporate research institutions that seek to align calculation costs and statistical resolution; institutions that perform the statistical spectacle of contemporary digital culture. On the other, could researching machine feeling be regarded as an interrogation of the failures of machine learning; or, even providing a methodology of failure that machine learning otherwise lacks?

This kind of research could take different shapes. For one, it might address the implied inclusions and exclusions that are at play in the politics of research, such as the intersectional feelings of race, gender, and class. It might address the emotionalisation of not only politics and a people born to feel (which seems to be intrinsically related to the statistical spectacle), but also of research itself and how it links to subjective patterns of experience. The contributions to the journal resonate with this approach and expose some of the fallacies at work in research processes once feelings are engaged. The subsections of this journal reflect this problem: making sense (lain Emsley, Maike Klein, Irina Raskin); (un)being (Maria Dada, Tiara Roxanne, Rebecca Uliasz, Brett
Zehner); feeling generators (Malthe Stavning Erslev, Michela De Carlo, Carman Ng, Tanja Wiehn); and seeing things (Mitra Azar, Daniel Chavez Heras, Tomasz Hollanek, Rosemary Lee, Carleigh Morgan).

There is more than a hint of Williams (and his cultural materialism) across these positions in recognition of the ways that certain ideas (such as affect theory and machine learning) achieve hegemonic status. We, as contributors to this journal issue, all feel/felt the weight of history and privilege here, not least as the workshop leading to the publication was held at the University of Cambridge where Williams himself once taught. The setting for our (and his) work is clearly an important issue if we take structures of feeling seriously and recognise that the contents of a journal such as this are a consequence of a wider factors that include actual work, social relations, and place of production: "it is a trivial fantasy to suppose that these general and pressing conditions are for long or even at all separable from the immediate and the personal", as Williams puts it (Culture and Materialism 222). Herein lies the tension between received forms and lived experience, of structures of feeling.

Thanks to all authors as well as further contributors to the workshop (Anne Alexander, Alan Blackwell, Anja Breljak, Jennifer Gabrys, Kristoffer Gansing, Leonardo Impett, Matteo Pasquinelli, Søren Pold, Winnie Soon, Magda Tyzlik-Carver, Martin Zeilinger), a collaboration between transmediale festival, Aarhus University, and Cambridge Digital Humanities Learning Programme.

We dedicate this issue to the memory of Sascha Pohflepp. 


\section{Works cited}

Pasquinelli, Matteo. "The Undetection of the New." Machine Feeling. University of Cambridge, 14 Jan. 2019. Keynote at workshop.

Sharma, Devika and Frederik Tygstrup. "Introduction." Structures of Feeling: Affectivity and the Study of Culture, edited by Devika Sharma and Frederik Tygstrup. Berlin: De Gruyter, 2015. Print.

Williams, Raymond. "Structures of Feeling." Marxism and Literature, Oxford: Oxford University Press, 1977, pp. 128-135. Print.

- Culture and Materialism: Selected Essays By Raymond Williams, London: Verso, 2005. Print. 